\title{
Perioperative fluid management of orthopaedic patients
}

\begin{abstract}
Intravenous (IV) fluid prescribing and giving is very important in the perioperative patient. It is commonly left to junior doctors and can sometimes be difficult. Errors in prescribing can lead to increased morbidity/ mortality and also increased stay in hospital. This paper aims to address concerns regarding perioperative fluid management including the assessment of fluid status and prescribing.
\end{abstract}

Volume 10 Issue 3 - 2018

\author{
Patel N, Sigamoney K, Balasubraniam D, \\ Wigan, Wrightington, Leigh \\ University of Cumberland Infirmary Carlisle, UK
}

\begin{abstract}
Correspondence: Kohila Vani Sigamoney, University of Cumberland Infirmary Carlisle, Northern Deanery, UK, Email kohilavani_sigamoney@yahoo.com
\end{abstract}

Received: February 04, 2018 | Published: June 05, 2018

\section{Importance of fluid management}

In the surgical field, fluid resuscitation and maintenance remains to be one of the most important facets of managing critically ill and patients admitted for surgery. It is also important in conditions like sickle cell to prevent crisis episodes,,$^{1,2,3}$ and in renal and cardiac failure where fluid overload can be an issue. ${ }^{4}$ Prescribing intravenous (IV) fluids is certainly under-appreciated and prescribing an IV fluid regimen can be a very complex issue and is commonly left for the more junior doctors. Errors made when prescribing IV fluids can lead to increased morbidity/mortality. Unfortunately errors in prescribing fluids are not commonly reported and therefore the importance of accurate prescribing often goes amiss.

\section{Physiology of fluid in the human body}

In the average human, the total body water accounts for around $60 \%$ of their total weight. So for example, a $70 \mathrm{~kg}$ man will have $42 \mathrm{~L}$ of total body water, of which two-thirds will be intracellular (28L) and one-third extracellular (14L). Furthermore, within the extracellular compartment, the fluid can be divided into intravascular $(2.8 \mathrm{~L})$ and extravascular (11.2L) compartments. Water can move freely between these compartments across the cell wall, which separates the intracellular and extracellular compartments, the capillary endothelium and walls of the arteries and veins, which separates the extracellular compartment from the intravascular and interstitial compartments. Add to this the multiple electrolyte needs of the body, making fluid management an important facet of patient care in hospital. ${ }^{5}$

\section{Principles behind IV fluid management}

The common reasons for intravenous fluid administration and the indications are as follows: ${ }^{6}$

1. Maintaining normal blood pressure

2. Returning the intracellular fluid volume to normal

3. Replace ongoing losses

4. Giving maintenance fluids for insensible losses

5. The need of glucose for the brain

The ideal resuscitation fluid would increase intravascular volume in a predictable and sustained manner, is chemically of a similar composition to that of extracellular fluid. It would also be metabolised and completely excreted by the body with no accumulation in tissues or any adverse side effects. Unfortunately the ideal fluid has not been created and so we need to manage effectively with the currently available crystalloids and colloids. ${ }^{7}$

\section{Crystalloids vs colloids}

Crystalloids are solutions of inorganic ions and small inorganic molecules dissolved in water, with the main solute being either glucose or sodium chloride. The solution can be isotonic, hypotonic or hypertonic compared with plasma. Crystalloids may have similar properties to that of plasma and so is considered to be a physiological similar fluid to that of plasma.

A colloid is different to crystalloids in that it consists of a noncrystalline substance with large molecules dispersed through a second substance. Colloids can either be semi-synthetic or naturally occurring human plasma derivatives. ${ }^{5}$

\section{Water balance}

In order to maintain a steady body weight, the relationship between fluid intake and fluid loss should roughly be equal. Fluid can be gained in various ways with the principle method being via oral intake and food, this accounts for approximately $2300 \mathrm{ml}$ of the $2500 \mathrm{ml}$ taken in on average. The rest of the $200 \mathrm{ml}$ coming from oxidation of hydrogen in food. In addition, fluid can be lost from multiple areas, including from the lungs, skin, sweat, faeces but mainly via urine, which accounts for roughly $1500 \mathrm{ml}$ of the $2500 \mathrm{ml}$ lost on average.

In normal well patients, they will be able to maintain their fluid status by balancing their output with their intake. However, in unwell patients, if intake is greater than output a positive water balance occurs and alternatively when output is greater than input a negative water balance occurs. An uneven water balance is particularly relevant in unwell patients as this may lead to oedema, which is not uncommon as a consequence of fluid therapy or dehydration which may also cause various complications. ${ }^{8}$

\section{Assessing hydration status}

Before administering fluids, it is important to also assess the patient's fluid status to ensure that the fluids are given over an 
appropriate period of time. The first part of assessing hydration is the clinical assessment. This includes:

1. Eliciting a history from the patient

a. Do they feel thirsty

b. If the patient is dehydrated they may complain of feeling light-headed, dizzy or symptoms of postural hypotension

1. Look at the observations chart

a. Blood Pressure (falls in dehydration)

b. Heart rate (increases in dehydration)

1. Skin temperature and texture

a. If dehydrated, the peripheries may be cool

2. Capillary refill time (CRT)

3. Skin turgor

4. Regular weights

Another method of assessing fluid status is the fluid balance charts, which is to assess the fluid intake and output. Intake includes oral intake, any IV fluids given and also from enteral feeding. With output being any fluid losses from the body, with the main source being urine, at around $1 \mathrm{ml} / \mathrm{kg} / \mathrm{hr}$. If the patient is producing urine anything less than $0.5 \mathrm{ml} / \mathrm{kg} /$ day then the patient needs some medical attention and is defined as oliguria.

Finally, it is also important to assess the patient's blood chemistry as this can be an indicator for dehydration but also to be wary of electrolyte imbalances. With dehydration urea and creatinine may rise to indicate renal damage. Furthermore, electrolyte imbalances are important to be aware of as a consequence of incorrect fluid management, which may lead to various morbidities. ${ }^{8}$

\section{Fluid resuscitation and maintenance}

It is important to identify causes of shock, including hypovolaemic and septic shock, as both are common in post-op surgical patients, as excessive blood loss is not uncommon and due to the body being at an increased risk of contracting an infection. There are multiple indicators of shock: tachycardia, hypotension, narrow pulse pressure, decreased capillary refill time, pale skin, increased skin turgor, low urine output and dry mucus membranes. It is vital to identify shock in elderly patients as they have a very small reserve to compensate for any loss in organ perfusion. ${ }^{9}$

In order to treat shock, aggressive fluid resuscitation is required. There has been continued debate as to whether a colloid or a crystalloid should be used. There have been multiple trials investigating this; a study by Parner et al., ${ }^{10}$ investigated the use of colloids and crystalloids in septic shock for around 800 patients and results showed that patients treated with colloids had an increased risk of mortality at day $90 .{ }^{10}$

In contrast, a large trial carried out for the investigation of fluid resuscitation in hypovolaemic shock of around 3000 patients by Annae et al., ${ }^{11}$ showed that there was no difference in 28 day mortality in patients treated with colloids and crystalloids and actually showed that colloids actually had a lower 90 day mortality. ${ }^{11}$

On the other hand, further notable trials have shown there to be no difference in mortality between the two subgroups of patients. ${ }^{12,13}$ There remains a debate as to whether crystalloids or colloids are used in fluid resuscitation but NICE guidelines do suggest that crystalloids are an adequate and preferred option for fluid resuscitation. ${ }^{14}$

\begin{tabular}{llll}
\hline Type of fluid & $\begin{array}{l}\text { Sodium } \\
\mathbf{m m o l} / \mathbf{L}\end{array}$ & $\begin{array}{l}\text { Potassium } \\
\mathbf{m m o l} / \mathbf{L}\end{array}$ & $\begin{array}{l}\text { Chloride } \\
\mathbf{m m o l} / \mathbf{L}\end{array}$ \\
\hline Plasma & $136-145$ & $3.5-5.0$ & $98-105$ \\
5\% Dextrose & 0 & 0 & 0 \\
Dextrose 4\% saline $0.18 \%$ & 30 & 0 & 30 \\
0.9\% normal saline & 154 & 0 & 154 \\
0.45\% 'half' normal & 77 & 0 & 77 \\
saline & 130 & 4 & 109 \\
Ringer's Lactae & 131 & 5 & 111 \\
Hartmann's & & & \\
\hline
\end{tabular}

The daily requirements of the body are approximately:
a. $25-30 \mathrm{ml} / \mathrm{kg} /$ day of water
b. $1 \mathrm{mmol} / \mathrm{kg} /$ day of potassium/sodium and chloride
c. $50-100 \mathrm{~g} /$ day glucose to limit starvation ketosis

Looking at the different compositions of electrolytes in the different fluids available, it shows the difficulty in meeting the daily requirements of the body. Unfortunately, there is no perfect fluid available to administer and emphasises the importance of regular biochemistry tests to ensure that all electrolytes are within safe levels.

\section{Fluid resuscitation and maintenance in paediatric care}

According to the NICE (National Institute for Health and Care Excellence) guidelines, if children and young people need IV fluid resuscitation, glucose-free crystalloids should be used. The recommended amount of sodium content in the fluid is in the range $131-154 \mathrm{mmol} / \mathrm{litre}$, with a bolus of $20 \mathrm{ml} / \mathrm{kg}$ over less than 10 minutes. Different fluid volumes may be needed in certain conditions like in cardiac or renal disease. ${ }^{15}$

Maintenance is suggested at $100 \mathrm{ml} / \mathrm{kg} /$ day for the first $10 \mathrm{kgs}$ of weight, $50 \mathrm{ml} / \mathrm{kg} /$ day for the next $10 \mathrm{kgs}$ and $20 \mathrm{ml} / \mathrm{kg} /$ day thereafter.

\section{Fluid resuscitation and maintenance in the elderly}

The main aim is to correct hypoperfusion and avoid fluid overload. Therefore adequate fluid resuscitation with clear end points should be practiced. This could be by assessing levels in blood tests, noninvasive monitoring or invasive monitoring. Assessment should also be frequent. ${ }^{16,17}$

\section{Complications of IV fluid management}

There are various complications from IV fluid therapy. As always, with any type of minimally invasive procedure which breaks the skin barrier, there is always a risk of infection infiltrating into the body. Furthermore, as the cannula would be inserted into the vein, there is also a risk of inflammation of the vein, called phlebitis. Another risk involving the cannula, is that there is always a chance of the cannula being displaced from inside the vein causing fluid extravasation. This is when the fluid enters the surrounding tissue and this can consequently become painful for the patient.

Once fluid has been administered into the veins, there can be further complications. A common complication is the important of recognising fluid overload. Fluid overload can present as pulmonary 
oedema as well as peripheral oedema, which should be picked up on clinical examination and treated appropriately.

Another important feature to be wary of during fluid therapy, especially with Hartmann's solution, is electrolyte imbalances. This includes potassium, sodium and also magnesium, it is important to monitor these levels as this can cause significant complications and so it is important to correct these levels within normal range.

\section{Post-operative fluid management}

The British Consensus Guidelines for Intravenous Fluid Therapy for Adult Surgical Patients (GIFTASUP) recommendations reflected the results of this audit. An important aspect which they identified was that the patients should not be receiving standard post-operative fluid management and should ideally be individualised for each patient. Also mentioned was the fact that fluid balance charts were often inaccurate and unreliable making fluid therapy even more difficult. Another important point made was that patients are often in positive sodium and fluid balance following surgery and so if the patient is euvolaemic following surgery, the target should be to allow for cautious excretion of sodium and water. This is reflected by a study by Herrod et al who investigated surgical patient's sodium balances and found that $4 \%$ developed dysnatraemias which contributed to patient mortality showing the importance of sodium balance. The study also reiterated that documentation was poor, weight of the patient was not routinely measured and all this would directly affect patient care. ${ }^{18}$

\section{Intravenous fluids audit}

To investigate the efficacy of IV fluid prescribing and whether or not it is done effectively, an audit looking at postoperative fluid management on orthopaedic patients was carried out. The sample size consisted of patients started on IV fluids following surgery over a one month period between November-December, of which data for 20 patients was gathered. The data was gathered from Day 1 up until Day 7 post-op and the proforma that was used was based on the proforma provided by NICE.

\section{Results}

One of the assessments of the audit was whether or not IV fluids were actually necessary or had they most likely just been continued without reassessment. Studies have shown that for an in-patient who are fluid depleted, hydration using oral ingestion compared to the intravenous route were equally effective as a form of rehydration. ${ }^{19}$ Furthermore, GIFTASUP also recommends to return to oral fluids as soon as possible following an operation. This shows that if the patient is drinking/able to drink an adequate amount of fluids then they should no longer be on intravenous fluids. The results of the audit showed that $80 \%$ of patients were given IV fluids when they could most likely maintain adequate amounts orally. This also stresses the importance of having an accurate strict input/output chart, which was not the case on the ward that was audited, to ensure that whether or not oral intake is adequate and also to monitor urine output.

After assessing the patient, if the conclusion was that the patient does require fluids, it is important to take into consideration the most recent blood biochemistry results to ensure the best fluid is prescribed. As shown in the table of constituents in the different fluids, it can be easy to cause electrolyte imbalances if given the wrong fluids The results of the audit showed that it is unlikely that this was done regularly as when bloods were checked retrospectively it was found that patients were hyperkalaemic but were still prescribed Hartmann's fluid, which can potentially cause serious morbidity.

The next step in fluid management is the documentation, it is important that the volume, rate and type of fluid is accurately documented on the prescription chart and also ideally to prescribe fluids for the next 24 hours. The 24 hour fluid prescription is a salient point as if not done, fluid management could be the responsibility of the on-call team and as they do not know the patient and has time constraints would be more likely to prescribe blindly in an attempt to save time, which again could lead to morbidity. This was another aspect of fluid management that was found to be particularly poor.

Additionally, it is key that the patient does not receive too much fluid in any given time as this can lead to the patient becoming overloaded and seriously unwell. The recommended volume is 20$25 \mathrm{ml} / \mathrm{kg} /$ day, which is much less than many people expect and as mentioned, patients that need special consideration are: paediatric patients, the elderly, those in renal/cardiac involvement and those malnourished. This was another aspect which was done poorly in my audit.

Next, is to ensure that the patient electrolyte balances are as normalised as possible. The recommended amounts include $1 \mathrm{mmol} /$ $\mathrm{kg} /$ day of potassium, sodium and chloride. This again would be difficult due to the constituents of the fluids available, but it is important that whatever bag is prescribed contains additional electrolytes if necessary.

Other notable points that was poor included, not assessing fluid balance before prescribing fluids, assessing fluid status, documented previous days input/output values, documentation as to why fluids have been started and also the importance of regular weight checks.

Not many of the patients that were audited required fluid resuscitation and so it is difficult to come up with any meaningful conclusions, but what is important that what not done in the few patients that did require resuscitation was to assess the patient using a systematic approach (for example the $\mathrm{ABCDE}$ approach; airwaybreathing-circulation-disability-everything else) and to then re-assess using the same approach after administering fluids.

The final and the most important conclusion was that fluid management is a vital aspect of patient care and if done incorrectly can lead to patient morbidity and potential mortality. Of the relatively small number of patients that were investigated, two patients actually had serious complications likely due to inappropriate fluid management. One patient went into pulmonary oedema and had been given much more than the recommended $25-30 \mathrm{ml} / \mathrm{kg} / \mathrm{day}$ of fluid and the other had hyperkalaemia following administration of Hartmann's fluid. This emphasises the importance of accurate fluid management.

\section{Conclusion}

Following the results of the audit it has been concluded that fluid management in hospitals is not performed very well and there is definitely scope for improvement. The multiple parameters that was audited showed standards were not met and subsequently that there were also complications as a result. The consequence of this is that 
it increases length of hospital admission impacting on health service resources and can also directly influence patient care. It is vital that the importance of fluid management is not neglected for better patient care.

\section{Acknowledgements}

None.

\section{Conflict of interest}

The author declares no conflict of interest.

\section{References}

1. Oni L, Dick M, Smalling B, et al. Care and management of your child with sickle cell disease-A parents' guide Brent Sickle Cell \& Thalassaemia Centre. 2nd ed. 2006.

2. UK Forum for Haemoglobin Disorders. Sickle Cell Disease in Childhood - Standards and Guidelines for clinical care. London: UK Forum; 2010.

3. Sickle Cell Society. Standards for the clinical care of adults with sickle cell disease in the UK. London: Sickle Cell Society; 2008.

4. Knott L. Fluid Overload. Patient. 2014.

5. Grocott MP, Mythen MG, Gan TJ. Perioperative fluid management and clinical outcomes in adults. Anesthesia and analgesia. 2005;100(4):1093106.

6. Shafiee MA, Bohn D, Hoorn EJ, et al. How to select optimal maintenance intravenous fluid therapy. QJM : An International Journal of Medicine. 2003;96(8):601-10.

7. Myburgh JA, Mythen MG. Resuscitation fluids. The New England journal of medicine. 2013;369(25):2462-3.
8. Scales K, Pilsworth J. The importance of fluid balance in clinical practice. Nursing standard. 2008;22(47):50-7.

9. Kobayashi L, Costantini TW, Coimbra R. Hypovolemic shock resuscitation. The Surgical clinics of North America. 2012;92(6):140323.

10. Perner A, Haase N, Guttormsen AB, et al. Hydroxyethyl starch 130/0.42 versus Ringer's acetate in severe sepsis. The New England journal of medicine. 2012;367(2):124-34.

11. Annane D, Siami S, Jaber S, et al. Effects of fluid resuscitation with colloids vs crystalloids on mortality in critically ill patients presenting with hypovolemic shock: the CRISTAL randomized trial. JAMA. 2013;310(17):1809-17.

12. Caironi P, Tognoni G, Masson S, et al. Albumin replacement in patients with severe sepsis or septic shock. The New England journal of medicine. 2014;370(15):1412-21.

13. Finfer S, Bellomo R, Boyce N, et al. A comparison of albumin and saline for fluid resuscitation in the intensive care unit. The New England journal of medicine. 2004;350(22):2247-56.

14. Intravenous fluid therapy in adults in hospital; 2013.

15. Intravenous fluid therapy in children and young people in hospital. 2015.

16. With elders, be cautious with fluid resuscitation. 2010.

17. Jacobs DG, Plaisier BR, Barie PS, et al. Geriatric Trauma: Parameters for Resuscitation. Journal of Trauma. 2003;54(2):391-416.

18. Herrod PJ, Awad S, Redfern A, et al. Hypo-and hypernatraemia in surgical patients: is there room for improvement? World journal of surgery. 2010;34(3):495-9.

19. Castellani JW, Maresh CM, Armstrong LE, et al. Intravenous vs. oral rehydration: effects on subsequent exercise-heat stress. Journal of applied physiology. 1997;82(3):799-806. 